\title{
Modified bacterial cellulose tubes for regeneration of damaged peripheral nerves
}

\author{
Karolina Kowalska-Ludwicka ${ }^{1,2}$, Jaroslaw Cala', Bartlomiej Grobelski ${ }^{1}$, Dominik Sygut ${ }^{3}$, \\ Dorota Jesionek-Kupnicka², Marek Kolodziejczyk², Stanislaw Bielecki², Zbigniew Pasieka ${ }^{1}$
}

${ }^{1}$ Department of Experimental Surgery, Medical University of Lodz, Poland ${ }^{2}$ Institute of Technical Biochemistry, Lodz University of Technology, Lodz, Poland ${ }^{3}$ Department of Pathology, Medical University of Lodz, Poland

Submitted: 5 April 2011

Accepted: 16 December 2011

Arch Med Sci 2013; 9, 3: 527-534

DOI: 10.5114/aoms.2013.33433

Copyright (c) 2013 Termedia \& Banach

\begin{abstract}
Introduction: The subject of the experiment was bacterial nanocellulose, a natural polymer produced by bacteria - Gluconacetobacter xylinus. Following a specific modification process a cartilage-like material for restoration of damaged tissues may be produced. The obtained implants with excellent biocompatibility, mouldability, biophysical and chemical properties perfectly fit the needs of reconstructive surgery. The goal of the experiment was to develop and analyze cellulosic guidance channels in vivo for the reconstruction of damaged peripheral nerves.

Material and methods: The experiments were conducted on Wistar rats, femoral nerve. Cellulose was produced according to a self-patented method. In the experimental group tubulization was applied, whereas in the control traditional end-to-end connection was used. Observation time was 30, 60, 90, and 180 days. Results evaluation included histological analysis and postoperative observation of motor recovery.

Results: The overgrowth of connective tissue and disorganisation of neural structures was evident in $86.67 \%$ of control specimens, while for cellulosic group it was only $35 \%(p=0.0022)$. Tubulization prevented the excessive proliferation of connective tissue and isolated from penetration with scar tissue. Autocannibalism, being probably an evidence of neurotrophic factors amassment, was observed in cellulosic group but not in the control one. Motor recovery did not differ significantly $(p>0.05)$. Biocompatibility of implants was affirmed by very small level of tissue response and susceptibility to vascularisation.

Conclusions: Cellulosic neurotubes effectively prevent the formation of neuromas. They are of very good biocompatibility and allow the accumulation of neurotrophic factors inside, thus facilitating the process of nerve regeneration.
\end{abstract}

Key words: bacterial nanocellulose, neurotube, peripheral nerve regeneration, in vivo biocompatibility.

\section{Introduction}

Contemporary knowledge and availability of materials significantly limit the possibilities of internal organ reconstruction. Currently applied polymeric substitutes (silicones, Gore-Tex, collagen, plastics) are being rejected due to their physicochemical properties, immunogenicity, or lack of vascularisation, and most often do not fulfil the role of the replaced organ [1, 2]. On the other hand, autologous grafts make operations rather complicated. The problem concerns the reconstruction of organs such as trachea

\author{
Corresponding author: \\ Karolina Kowalska-Ludwicka PhD \\ Institute of Technical \\ Biochemistry \\ Lodz University \\ of Technology \\ 4/10 Stefanowskiego St \\ 90-924 Lodz, Poland \\ Phone: +48 4263133 67, \\ +48426313442 \\ E-mail: \\ karolina.ludwicka@p.lodz.pl
}


and peritoneum, as well as the restoration of damaged peripheral nerves. The Department of Experimental Surgery of the Medical University of Lodz in cooperation with the Institute of Technical Biochemistry of the Technical University of Lodz proposes modified bacterial cellulose as a material for organ and tissue reconstruction. Physicochemical properties, susceptibility to vascularisation and good biocompatibility make this material perfect for such purposes.

Owing to its unique properties microbial cellulose has already been found to have a great potential in the wound healing process (e.g. CelMat ${ }^{\oplus}$ and XCell ${ }^{\oplus}$ [3-6]. They are applied as either dehydrated or never-dried wound dressings accelerating the process of healing and facilitating scar formation. Biocompatibility, porosity, mouldability, transparency, great adherence and protection from secondary infections, lack of sticking to the regenerated tissue, exudation adsorption capabilities and water holding capacity (optimum humidity conditions), pain mitigation by heat adsorption (important in burns healing), all these features meet the standards and requirements for modern dressings $[3,4]$.

On the other hand, the size of hollow spaces within the cellulose network and lack of swelling effect fit the needs for internal applications of this material. Recent investigations on microbial cellulose in vivo biocompatibility indicate further research concerning its usage in surgery $[7,8]$.

The specific features of this polymer have been recently the subject of many investigations. Research is performed simultaneously on its biocompatibility as well as on its different applications in tissue scaffold engineering [8-12]. Bacterial cellulose has already been successfully employed in dentistry as a dental implant to recover periodontal tissues (Gengiflex ${ }^{\oplus}$ [3, 5]. The effect of experimental cooperation of chemists, biologists and surgeons gave rise to artificial blood vessel design. Bacterial synthesized cellulose - BASYC ${ }^{\circledR}$, described by Klemm et al. - developed as the result of direct shaping procedures during the cultivation process (in situ modification), and as a nonthrombogenic material has a great potential for applications in microsurgery, in blood vessel as well as large artery replacement $[10,11,13,14]$. Tubes are grown in stationary culture in the form of a pellicle with a glass mandrill put vertically into the membranes. The ability of diameter regulation gives an opportunity to apply them also in other fields, such as neurosurgery. Bacterial cellulose implanted as a protective cover of fascicles seems to prevent the gaps between the anastomosed nerve ends from connective tissue ingrowth, and thus enables signal conduction $[10,13,14]$. Nevertheless, as yet no specific results of evaluation of this technique have been presented.

The second example of cylindrical shaping of cellulose for blood vessel substitution was given by
Bodin et al. In this case the fermentation process is performed within silicone tubes of different sizes, where the thickness of the cellulose wall is dependent upon the oxygen ratio [15-17]. Such a method, contrary to $\mathrm{BASYC}^{\oplus}$ tube production, has no limitation on the tube length. On the other hand, the cultivation conditions strongly influence cellulose structure, membrane uniformity and mechanical properties, which are of great importance for surgical purposes.

The workers of the Department of Experimental Surgery together with the Institute of Technical Biochemistry have made an attempt to create and examine a novel tube made of microbial cellulose designed for regeneration of damaged peripheral nerves.

Taking advantage of the water holding capabilities, also chemical modifications of cellulosic membranes are possible. At the Technical University of Lodz such post-production methods have recently been the subject of intensive analysis. Cellulosic membrane is highly gelatinous since water constitutes at least $95 \%$ of its weight $[18,19]$. However, in spite of high water-binding capacity most of the water is not bound to the polymer, which enables squeezing out by gentle pressing. Such mechanical compression enables the production of wound dressings of different sizes and shapes [4, 5, 20]. If not compressed, membranes may be specifically shaped and subjected to a mercerization process, resulting in formation of cartilage-like constructs of different sizes and forms [21-24]. Tubular ones may serve as neurotubes guiding the regeneration of damaged peripheral nerves.

The goal of the experiment was to develop and analyse in vivo cellulosic guidance channels for the reconstruction of damaged peripheral nerves. Analysed neurotubes ought to limit the formation of traumatic neuromas, formed due to the insufficient reparative process, which clinically are observed as small nodules at the anastomosis site. They significantly lower the ability of neural conductivity restoration, making full functional recovery of the disabled nerve much longer or even impossible.

Therefore, implanted prostheses should accelerate the process of regeneration more effectively as compared to standard surgical methods.

\section{Material and methods}

\section{Production of cellulosic tubes}

The process of modification of cellulosic membranes into a cartilage-like substitute became the subject of European Patent Application [24]. It involved a cultivation and purification step, already elaborated by the workers of the Institute of Technical Biochemistry [20]. The post-production modification stage comprised mercerization and the mechanical shaping procedure. 
Bacterial cellulose pellicles, with thickness of about 10-15 mm, formed on Schramm-Hestrin medium and purified were cut into rectangular pieces (approx. $10 \mathrm{~mm} \times 10 \mathrm{~mm} \times 30 \mathrm{~mm}$ ) which, one by one, were impaled onto stainless steel needles (1.2 $\mathrm{mm}$ in diameter) and slightly squeezed by rolling. Such fragments underwent alkali treatment. They were kept in $20 \% \mathrm{NaOH}$ solution for $24 \mathrm{~h}$ or as long as water rinsing from cellulosic fibres proceeded. Cellulosic pieces shrank, losing about 50-60\% of their length and diameter, and became more and more compact in structure. After mercerization they were washed under tap water and, if needed, shaped by cutting into more rounded fragments. Purified and moulded tubes (Figure 1) were taken off the needles, put into distilled water and after $\mathrm{pH}$ adjustment ( $\mathrm{pH} 7.0)$, autoclaved following the methods already elaborated for other cellulose-based medical products $\left(25 \mathrm{~min}, 120^{\circ} \mathrm{C}\right)[7,16]$.

\section{Surgical procedures}

In vivo analyses were performed on Wistar rats (female, up to $150 \mathrm{~g}$ ). All the procedures were carried out according to Local Ethical Commission agreement (No. 30/ŁB369/2007).

Animals were anesthetised with ketamine delivered intraperitoneally in a dose of $20 \mathrm{mg} / \mathrm{kg}$ c.c. Sutures applied included Premilene ${ }^{\oplus} 7 / 0$ for nerve and Monosof ${ }^{\mathrm{TM}}$ 4/0 for skin suturing. Cellulosic tubes designed for implantation were about $9 \mathrm{~mm}$ in length, with $1 \mathrm{~mm}$ hole diameter and wall thickness of 1-1.5 mm. In the cellulosic group (30 rats) the tubes were thread onto the cut femoral nerve by means of reins (Premilene ${ }^{\circledR} 7 / 0$ ), which were attached to the nerve ends and reeved through the tube lumen (Figure 2). By pulling the reins through the hole of the tube, the nerve stumps were drawn inside, with space left between them, and then stabilised with four single sutures via epineurium to the tube wall. In the control group (24 rats) traditional end-to-end connection with single loop suture was applied. The observation time was 30, 60, 90 and 180 days. The evaluation of recovery changes was based on postoperative observation of disabled limb movement. To avoid self-injuring, that is eating off digits of operated legs (autocannibalism), the animals were given an analgesic solution (metamizole inj.) in doses of $0.5 \mathrm{~g}$ per $100 \mathrm{ml}$ of drinking water every day for two months following transection. Subsequently, before explantation at each observation time point they were killed by giving an overdose of ketamine delivered as previously.

\section{Motor recovery assessment}

The recovery of operated limbs was evaluated according to the Medical Research Council System for grading nerve recovery $[25,26]$. The scale based on this system served to estimate the degree of

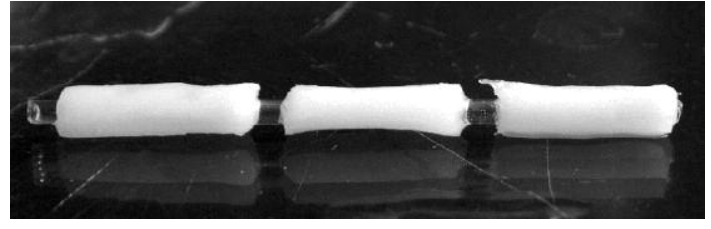

Figure 1. Modified bacterial cellulose in the form of tubes

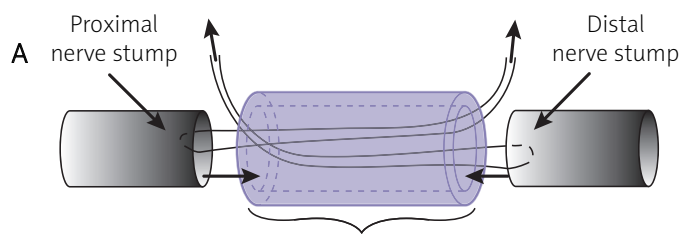

Nerve guidance channel

B

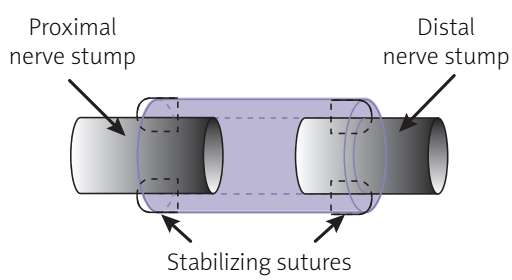

C

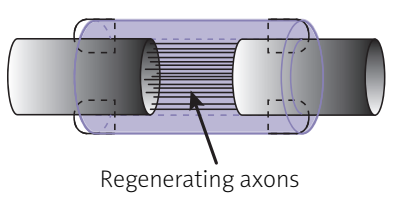

Figure 2. Surgical procedures applied during the stabilization of bacterial cellulose nerve guidance channels at the site of the nerve injury: A - threading, B - stabilisation with four epineural sutures, $\mathrm{C}$ - regeneration of axons

disabled leg movement ability after 30, 60, 90 and 180 days (Table I). The animals were given scores from 1 to 5 (exact to 0.5 ) so as to find the average describing each investigated group. To avoid subjectivism the examination and limb movement evaluation was performed by two independent observers.

\section{Histology}

Microscopic evaluation was based on hematoxylin-eosin (HE) staining for tissue-biomaterial interaction as well as S-100 immunohistochemical treatment for the purpose of neuron growth observation. All stainings were performed according to the procedures applied in the Pathology Department (Medical University of Lodz) used routinely in daily diagnostics. Explanted samples (nerves enclosed by cellulosic tubes) were formalin fixed and then paraffin embedded. Serial 5 - $\mu$ m-thick tissue sections cut from paraffin blocks were mounted individually onto charged glass slides. One slide of each case was hematoxylin-eosin stained for the purpose of microscopic evaluation of the tissue immune response. Immunohistochemical reaction for S-100 protein was performed in order to evaluate 
Table I. The scale for grading motor recovery of the operated limbs

\begin{tabular}{|cl|}
\hline \multicolumn{1}{|c|}{ System for grading nerve motor recovery } \\
\hline 0 & No contraction (total palsy of the limb) \\
\hline 1 & Return of perceptible contraction in the proximal muscles (limb palsy below the elbow, dragging of foot) \\
\hline 3 & $\begin{array}{l}\text { Return of perceptible contraction in the proximal and distal muscles (ability to move the foot during walking) } \\
\text { to act against gravity (ability to resist weak mechanical force and stand on disabled foot) }\end{array}$ \\
\hline 4 & $\begin{array}{l}\text { All muscles act against strong resistance and some independent movements are possible (disabled foot strong enough } \\
\text { to push back during walking, slight contraction of fingers) }\end{array}$ \\
\hline 5 & Full recovery of all muscles (difference between healthy and operated limb hardly visible) \\
\hline
\end{tabular}

the neuron outgrowth and neuroma formation. A positive reaction was considered as simultaneous tint of nucleus and cytoplasm of neural cells (background and fibroblast were negative, only counterstained with hematoxylin) [27, 28]. Neuroma formation was described as excessive growth of connective tissue at the scar formation site together with loss of peripheral nerve regular structure (general disorder of growing nerve cells) [29].

\section{Statistical analysis}

For motor recovery results analysis the MannWhitney $U$ test was used. In the case of S-100 examination, due to the low number of evaluable samples in the investigated times of observation, the analysis of significance of neuromas distribution changes in time was pointless. For that reason statistical analysis was confined to the total number of neuromas in each group and applied $\chi^{2}$ test.

\section{Results}

A total of 54 rats underwent surgical treatment; 49 of them were histologically evaluable. Two rats from the control group died postoperatively due to infection and three rats from the cellulosic group had to be killed because of self-mutilation. None of the control rats revealed self-injuring, while some of the cellulosic ones ate their own digits. In most cases the proper dose of analgesic solution prevented such behaviour.

Motor recovery observation was performed every 30 days following the surgery up to explantation time. It confirmed that the movement recovery increased in time in both investigated groups. The contracture of disabled digits could be seen in the majority of cases from both groups regardless of the score. After 180 days of implantation as many as $50 \%$ of animals with cellulosic tubes were given 4 (average 3.75 ) while in controls only $16.7 \%$ reached this level (average: 3.33) (Table II). However, statistical analysis showed no significant difference $(p>0.05)$ in average leg movement ability between control and cellulosic groups at given time points (Figure 3).

Considering explant analyses, for the control group samples were taken in a total number of 22 ( 2 after 30 days, 5 after 60 days, 10 after 90 days and 5 after 180 days). Consequently, for the cellulosic group 27 samples were explanted (3 rats were killed after 30 days, 6 after 60 days, 10 after 90 days and 8 after 180 days). The explantation procedure

Table II. Comparison of motor recovery and the number of neuromas in the control and bacterial cellulose group

\begin{tabular}{|lcccccc|}
\hline $\begin{array}{l}\text { Reconstruction } \\
\text { method }\end{array}$ & $\begin{array}{c}\text { Observation } \\
\text { time } \\
\text { [days] }\end{array}$ & $\begin{array}{c}\text { Number } \\
\text { of operated } \\
\text { rats }\end{array}$ & $\begin{array}{c}\text { Average } \\
\text { motor } \\
\text { recovery }\end{array}$ & $\begin{array}{c}\text { Number } \\
\text { of explants }\end{array}$ & $\begin{array}{c}\text { Number } \\
\text { of evaluable } \\
\text { samples }\end{array}$ & $\begin{array}{c}\text { Number } \\
\text { of neuromas } \\
\text { [\%] }\end{array}$ \\
\hline Control (end-to-end connection) & 30 & 4 & 0.50 & 2 & 2 & 100.00 \\
\cline { 2 - 7 } & 60 & 5 & 1.10 & 5 & 3 & 100.00 \\
\hline & 90 & 10 & 2.60 & 10 & 7 & 85.71 \\
\hline Total & - & 24 & - & 22 & 15 & 86.67 \\
\hline Bacterial cellulose tubes & 30 & 5 & 0.48 & 3 & 3 & 100.00 \\
& 60 & 6 & 1.48 & 6 & 4 & 75.00 \\
\hline & 90 & 11 & 2.47 & 10 & 8 & 0.00 \\
\hline Total & 180 & 8 & 3.75 & 8 & 5 & 20.00 \\
\hline
\end{tabular}


was carried out after the animals had been killed so that the operative field could be wide enough not to destroy the explants and to avoid a second nerve injury. During explantation no visible signs of infections or inflammation were observed. The tubes were easy to isolate during the explant preparation since the nonporous structure of microbial cellulose prevented deep penetration and subsequent concrescence surrounding tissues. Analysed tubes did not change their original size and shape. They were finely overgrown with a thin layer of connective tissue and newly formed small blood vessels (Figure 4 B). Several neuromas could be seen macroscopically; particularly in some control animals a small bulge was observed at the scar formation site (an example is presented in Figure $4 \mathrm{~A}$ ).

Close histological examination revealed that 3 cellulosic explants, taken after 90 days, were infected, with chronic inflammation visible within the tube. Sixteen specimens were smashed during preparation and could not be further evaluated. The remaining 15 control sections and 20 cellulosic ones underwent S-100 staining.

In HE specimens no granulation tissue could be observed in control samples. In the case of cellulosic tubes the thickness of granulation at the nerve-material interface varied from $1-2$ cells (low reaction) in almost $67 \%$ of cases (including 30 -day specimens) (Figure $5 \mathrm{~A}$ ) to $3-4$ cells (moderate reaction) in $11 \%$ of samples. These results were analogous for all observation time points. After 180 days of implantation

A

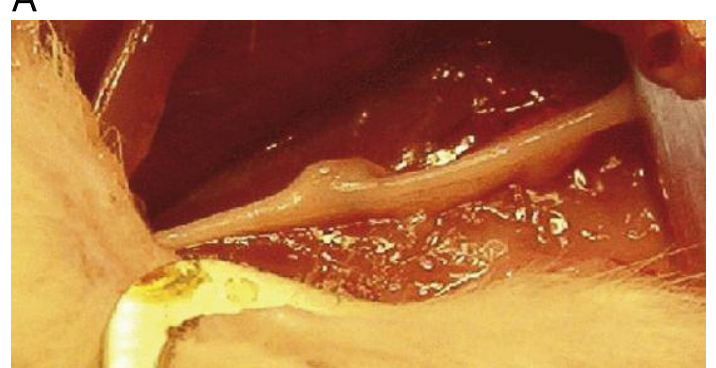

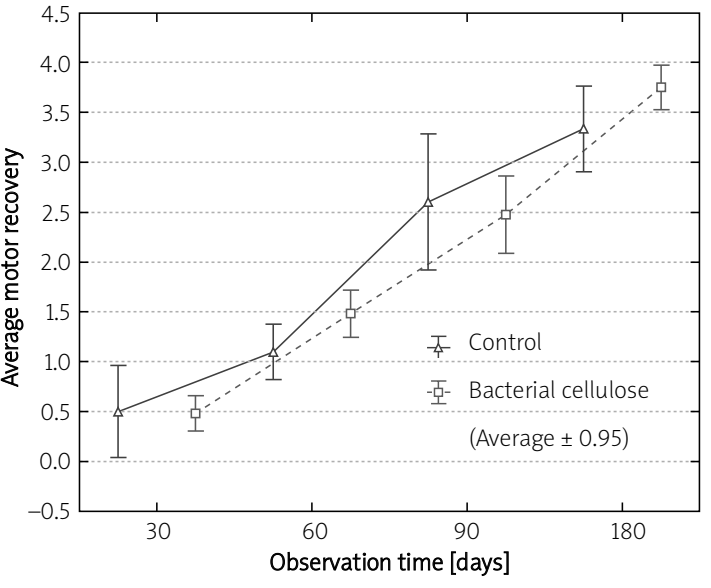

Figure 3. The difference in average motor recovery between the control and bacterial cellulose group after 30, 60, 90 and 180 days of observation

cellulosic implants tended to undergo fibrosis with almost no granulation visible (Figure $5 \mathrm{~B}$ ).

S-100 staining showed a significant difference in neuroma formation between the two experimental groups (Figure 6). The overgrowth of connective tissue and disorganisation of neural structures was evident in $86.67 \%$ of control specimens, while for the cellulosic group it was only $35 \%$ of evaluable samples (see Table II, Figure 7). The results of statistical analysis showed that the difference in the total number of neuromas between both investigated groups was statistically significant $(p=0.0022)$.

B

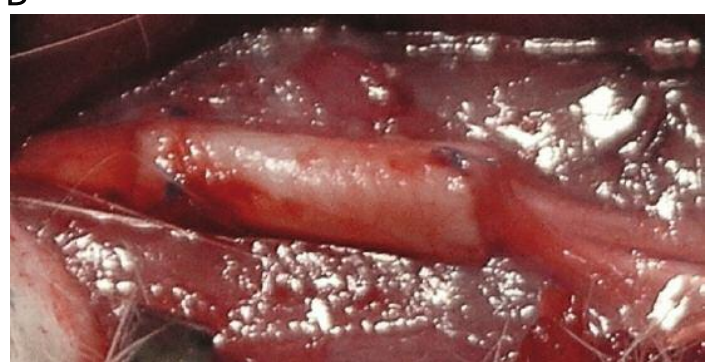

Figure 4. Macroscopic view of explants: A - control group after 30 days, neuroma visible as a nodule at the connection site; $\mathrm{B}$ - bacterial cellulose tube overgrown with newly formed blood vessels after 90 days of implantation

A

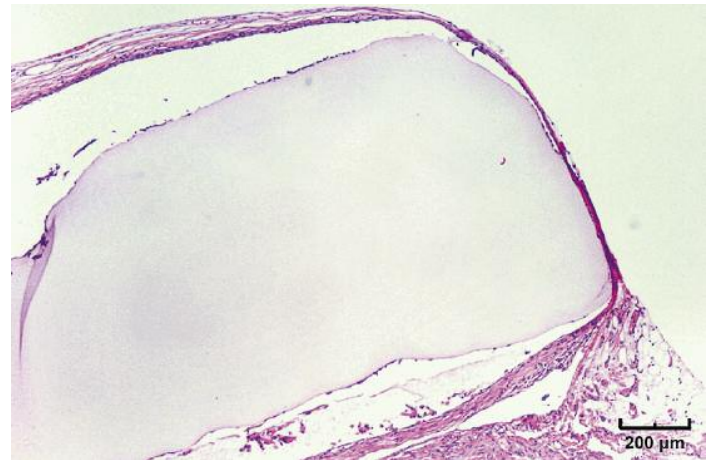

B

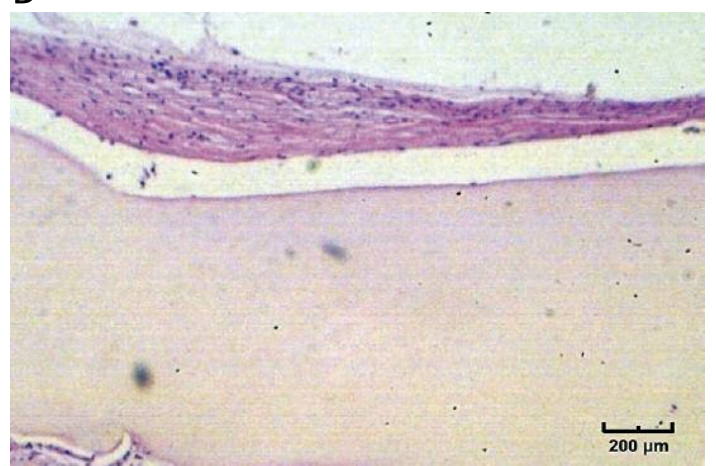

Figure 5. Explanted bacterial cellulose neurotubes with low tissue reaction after 90 days of implantation (A), and fibrotic tissue formed around the tube after 180 days (B) ( $\mathrm{H}+\mathrm{E}$ stain) 


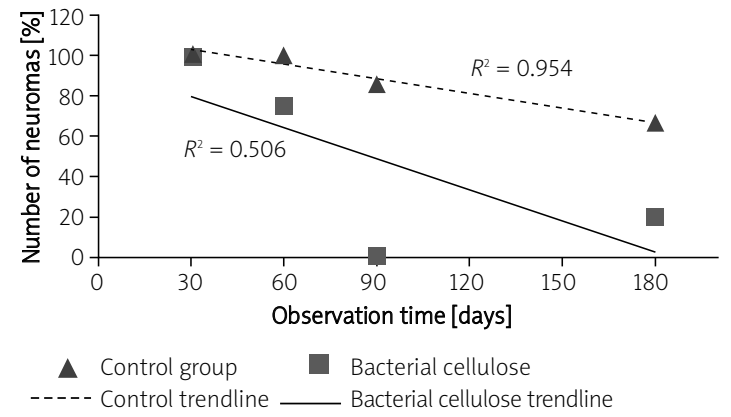

Figure 6. Changes in the number of neuromas versus time for the control and bacterial cellulose group after 30,60, 90 and 180 days of observation

\section{Discussion}

The problem of nervous tissue reconstruction still remains a challenge for today's medicine. Endto-end anastomosis and transplantations are considered to be the gold standards in the treatment of traumatic and iatrogenic damage of peripheral nerves [25]. However, poor recovery of damaged peripheral nerves (up to $80 \%$ ) inclines scientists to search for better methods of treatment, among which tubulization seems to be the most promising [31]. An implant in the form of a cylinder placed at the site of injury is expected to stabilize and support the repair processes. Such scaffolds are constructed mostly of synthetic and/or natural polymers and form a kind of a channel insulation for diffusing growth factors, while reducing the resulting infiltration with scar tissue and preventing the formation of neuroma [31, 32]. Bacterial cellulose, as a natural polymer, was found to be the perfect candidate for such a purpose, since it is much more biocompatible and provokes incomparably less immune response than the polymers already applied in reconstructive surgery [8-11, 13]. Confirming the results presented in the literature, biocompatibility of investigated cellulose implants was affirmed by the low level of tissue response and susceptibility to vascularisation and overgrowth with host connective tissue. Analysed tubes gave little granulation tissue formation at the implant site (after 180 days almost disappearing) [7, 8, 10, 13]. During the experiments there have been no rejections of implants, which is evidence that bacterial cellulose is well accepted by host organisms and suits the requirements for successful treatment of neural disorders. Its favourable influence on nervous tissue regeneration was confirmed by the fact that the restoration of damaged nerve fibres was observed even after 30 days of implantation. What is more, neurotubes made of bacterial cellulose applied in vivo significantly lowered the formation of neuroma. Both the macroscopic and histological outcome confirmed that the tubulization by means
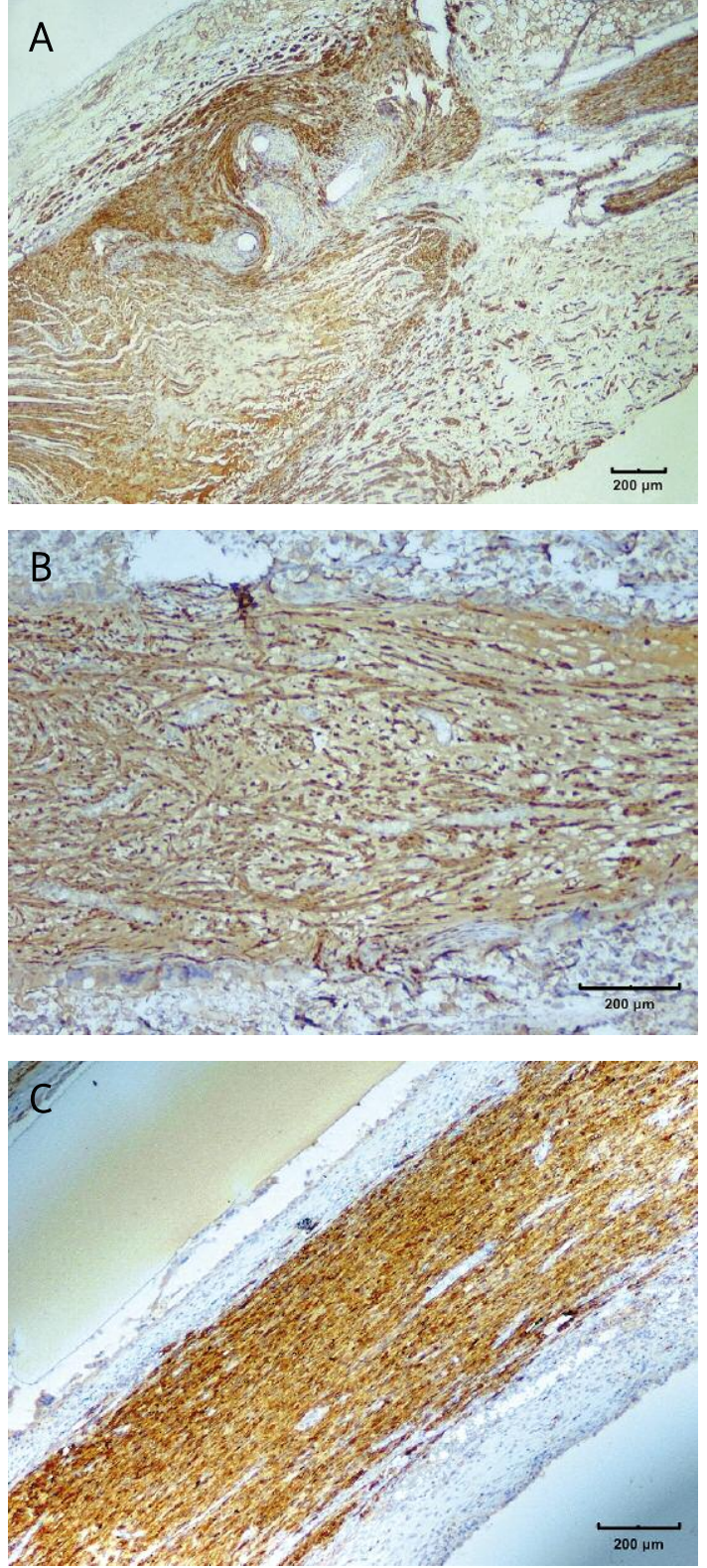

Figure 7. The results of S-100 staining: $\mathrm{A}$ - the overgrowth of connective tissue forming neuroma in the control group; $\mathrm{B}$ - the neuroma formed inside the tube, visible disorganisation of regenerating nerve fibres; $\mathbf{C}$ - properly regenerated nerve without the neuroma inside the cellulosic tube

of cellulosic tubes prevented the excessive proliferation of connective tissue and provided successful guiding of the growing axons. However, since modified cellulose tubes were rather inflexible and might not fit exactly the diameter of a given nerve, there was no possibility to avoid infiltration with body fluids and the development of connective tissue inside the tube was inevitable. Yet, if the stabilization method and a scaffold applied were conducive for the growth of axons, the growing cone pushed the obstacles, i.e. the fibres of connective tissue, aside. When the axons were properly guided, after some 
time the cluster that had formed between the stumps at the beginning of the process became visible only as a tissue surrounding the nerve, not the neuroma itself. For that reason, histologically only the concretion by means of connective tissue, not the nerve surrounded by these fibres, was considered to be a neuroma (Figure 7). Following such reasoning and assuming that the regeneration process inside the cellulose tubes proceeded properly, it is explicable that the number of neuromas formed decreased in time (Figure 6).

Discussing the results of the animal observations, the main problem that appeared during the experiment was autocannibalism, recorded in the cellulosic group but not in the control one. The molecular background and the causes of this phenomenon are still unexplained. Following Kryger et al. it could be evidence of amassment of neurotrophic factors, among others nerve growth factor (NGF). It is probable that the accumulation of NGF is responsible for neuropathic pain development and subsequently for self-injury occurrence in experimental animals $[29,30]$. The fact that analgesic solution administration in most cases prevented this problem supports such a hypothesis. On the other hand, one may deduce that cellulosic tubes also favour the accumulation of other growth factors promoting the regeneration of damaged nerve, which in turn is an advantage for their potential clinical application.

Considering the functional examination, motor recovery in the rats with neurotubes did not proceed much faster than in the case of end-to-end connection. The main reasons for that were probably the excessive rigidity of the implants (as compared to the relatively small size of female rat's feet) in conjunction with high invasiveness of the surgical procedure and the duration of surgery (tubulization was much more time-consuming). As a consequence muscle damage and subsequent atrophy could be observed. Most likely, in this kind of assessment the rehabilitation of disabled limbs is necessary to monitor the actual state of motor recovery. However, to confirm this assumption further analyses are required. It is likely that experiments on a larger animal model would make such an analysis easier. Also expanding the research to sham operated animals, where the surgery would imitate the time and conditions of the neurotube implantation without causing any nerve damage, might verify these assumptions and give an insight into this issue.

In conclusion, application of neurotubes produced from modified bacterial cellulose effectively prevents the formation of neuroma. The investigated material is of very good biocompatibility, allows proper guidance of the growing axons and is conducive to accumulation of neurotrophic factors inside, thus facilitating the process of nerve regeneration. It is likely that the application of growth factors immobilized within cellulosic fibres will be even more promising.

\section{Acknowledgments}

This work has been financed by the Ministry of Science and Higher Education, Poland, grant 1953/ B/P01/2008/35, and from the European Social Fund and the State Budget within Activity 2.6 of the Integrated Operational Program for Regional Development in connection with the execution of the project "Fellowships to support innovative research of PhD students".

\section{References}

1. Jagur-Grodzinski J. Polymers for tissue engineering, medical devices, and regenerative medicine. Concise general review of recent studies. Polym Adv Technol 2006; 17: 395418.

2. Ciardelli $G$, Chiono V. Materials for peripheral nerve regeneration. Macromol Biosci 2006; 6: 13-26.

3. Hoenich N. Cellulose for medical applications. Bioresources 2006; 1: 270-80.

4. Czaja W, Krystynowicz A, Bielecki S, Brown RM. Microbial cellulose - the natural power to heal wounds. Biomaterials 2006; 271: 145-51.

5. Bielecki S, Kalinowska H, Krystynowicz A, Kubiak K, Kołodziejczyk M, De Groeve M. Wound dressings and cosmetic materials from bacterial nanocellulose. In: Bacterial nanocellulose: a sophisticated multifunctional material. Perspectives in nanotechnology. Gama M, Gatenholm P, Klemm D (eds.). Boca Raton, Florida: CRC Press 2012; 157-74.

6. Krystynowicz A, Czaja W, Bielecki S, Kolodziejczyk M. A method for the production of bacterial cellulose, a method of immobilising bacteria, a method for the production of immobilised biocatalysts, and application of bacterial cellulose, a method for the modification of cellulose membranes. International patent application No. PCT/PL 2004/000051, 2004.

7. Helenius G, Bäckdahl H, Bodin A, Nannmark U, Gatenholm P, Risberg B. In vivo biocompatibility of bacterial cellulose. J Biomed Mater Res A 2006; 76: 431-8.

8. Mendes PN, Rahal SC, Pereira-Junior OC, et al. In vivo and in vitro evaluation of an Acetobacter xylinum synthesized microbial cellulose membrane intended for guided tissue repair. Acta Vet Scand 2009; 51: 1-9.

9. Yamanaka S, Ono E, Watanabe K, Kusakabe M, Suzuki Y. Hollow microbial cellulose, process for preparation thereof, and artificial blood vessel formed of said cellulose. European Patent No. 0396344, 1990.

10. Klemm D, Schumann D, Udhardt U, Marsch S. Bacterial synthesized cellulose - artificial blood vessels for microsurgery. Prog Polym Sci 2001; 26: 1561-603.

11. Wippermann J, Schumann D, Klemm D, Kosmehl H, Salehi-Gelani S, Wahlers T. Preliminary results of small arterial substitute performed with a new cylindrical biomaterial composed of bacterial cellulose. Eur J Vasc Endovasc Surg 2009; 37: 592-96.

12. Pasieka Z, Kowalska K, Grobelski B, Lawniczak P. Current use of modified bacterial cellulose in reconstructive surgery. Br J Surg 2008; 95 (S6): 40-1.

13. Klemm D, Ahrem H, Kramer F, Fried W, Wippermann J, Kinne RW. Bacterial nanocellulose hydrogels designed as bioartificial medical iplants. In: Bacterial nanocellulose: a sophisticated multifunctional material. Perspectives in 
nanotechnology. Gama M, Gatenholm P, Klemm D (eds.). Boca Raton, Florida: CRC Press 2012; 175-96.

14. Klemm D, Udhardt U, Marsch S, Schumann D. Method and device for producing shaped microbial cellulose for use as biomaterial, especially for microsurgery. U.S. Patent No. 0013163A1, 2003.

15. Bodin A, Backdahl H, Gustafsson L, Gatenholm P. Manufacturing and characterization of bacterial cellulose tubes using two different fermentation techniques. In: Modern multidisciplinary applied microbiology: exploiting microbes and their interactions. Mendez-Vilas A (ed.). Wiley-VCH, Weinheim 2006; 806: 619-22.

16. Bodin A, Backdahl H, Fink H, Gustafsson L, Risberg B, Gatenholm P. Influence of cultivation conditions on mechanical and morphological properties of bacterial cellulose tubes. Biotechnol Bioeng 2007; 97: 425-34.

17. Jia S, Tang W, Yang H, Jia Y, Zhu H. Preparation and characterization of bacterial cellulose tube. Proceeedings of the 3rd International Conference on Bioinformatics and Biomedical Engineering; 2009 Jun 11-13; China, Beijing. USA, IEEE Xplore 2009.

18. Bielecki S, Krystynowicz A, Turkiewicz M, Kalinowska H. Bacterial cellulose. Biopolym 2001; 5: 37-90.

19. Brown RM. Cellulose structure and biosynthesis. Pure Appl Chem 1999; 71: 767-75.

20. Galas E, Krystynowicz A. Method of bacterial cellulose production. Polish Patent No. 171952, 1997.

21. Grobelski B, Kopeć K, Kołodziejczyk M, Kuzdak K, Kowalska K, Pasieka Z. Surgical methods of modified bacterial cellulose use in reconstruction of trachea on rats. Langenbeck's Arch Surg 2009; 394: 1144.

22. Kowalska K, Grobelski B, Cała J, et al. Neurotubes from microbial cellulose for regeneration of damaged peripheral nerves - on animal model. Langenbeck's Arch Surg 2009; 394: 1146.

23. Shibazaki H, Kuga S, Okano T. Mercerization and acid hydrolysis of bacterial cellulose. Cellulose 1997; 4: 75-87.

24. Bielecki S, Kołodziejczyk M, Krystynowicz A, Kowalska K, Pankiewicz T. A method of production of a cartilagelike biomaterial designed for reconstructive surgery"; EP2371401 (A2), 2011.

25. Rowshan K, Jones NF, Gupta R. Current surgical techniques of peripheral nerve repair. Oper Tech Orthop 2004 14: 163-70.

26. Medical Research Council, Nerve Injuries Committee. Aids to Investigation of Peripheral Nerve Injuries. MRC War memorandum No.7 His Majesty's Stationery Offce, 1943. London, Balliere Tindall, 1986.

27. Tashiro A, Imafuku S, Furue M. Traumatic neuroma of the lower lip with intraepithelial nerve fibers. J Cutan Pathol 2008; 35: 320-3.

28. Folta R, Klima K, Spackova J, Sedy J. Mechanism of traumatic neuroma development. J Med Hyp 2008; 71: 572-6.

29. Kryger GS, Kryger Z, Zhang F, Shelton DL, Lineaweaver WC, Buncke HJ. Nerve growth factor inhibition prevents traumatic neuroma formation in the rat. J Hand Surg 2001; 26: 635-43.

30. Ro LS, Chen ST, Tang LM, Jacobs JM. Effect of NGF and anti-NGF on neuropathic pain in rats following chronic constriction injury of the sciatic nerve. Pain 1999; 79: 265-74.

31. Huang YC, Huang Y. Biomaterials and strategies for nerve regeneration. Artif Organs 2006; 30: 514-22.

32. Evans GR. Peripheral nerve injury: a review and approach to tissue engineered constructs. Anatomical Record 2001; 263: 396-404. 